\title{
BREVES REFLEXÕES SOBRE A HISTÓRIA DO DIREITO PROPRIEDADE NO BRASIL (SÉCULO XVI AO XIX)
}

\section{Ana Luisa Santos Rocha*}

Resumo: Considerando que os processos de continuidades e descontinuidades são premissas da análise histórica do direito de propriedade, o presente artigo tem como objetivo apresentar elementos da construção histórica do direito de propriedade no Brasil, com foco específico nos regimes dos séculos XVI ao XIX. Quanto à metodologia da pesquisa, trata-se de pesquisa exploratória e abordagem histórico-jurídica. Na primeira seção são apresentadas discussões sobre o regime sesmarial e nas duas seções seguintes, discussões sobre o período Imperial e sobre a construção da propriedade moderna no Brasil.

Palavras-chave: Direito de Propriedade; Análise Histórica; Regime Sesmarial; Lei de Terras de 1850; Propriedade Moderna.

\section{BRIEF REFLECTIONS ON THE HISTORY OF PROPERTY LAW IN BRAZIL (16TH TO 19TH CENTURY)}

\begin{abstract}
Considering that the processes of continuities and discontinuities are premises of the historical analysis of property rights, this article aims to present elements of the historical construction of property rights in Brazil, with a specific focus on regimes from the 16th to the 19th centuries. As for the research methodology, it is an exploratory research with a historical-legal approach. In the first section, discussions about the sesmarial regime are presented and in the next two sections, discussions about the Imperial period and about the construction of modern property in Brazil.
\end{abstract}

Keywords: Property right; Historical Analysis; Sesmarial regime; Land Law of 1850; Modern Property.

\section{Introdução}

Diferente das noções de "linearidade", "evolução" e "continuidade", a noção de propriedade é profundamente histórica (FONSECA, 2005) e não linear. Assim, sendo uma história descontínua, como pensar a história do direito de propriedade pelo marco da mera continuidade de formas (GROSSI, 2006)?

As novas leituras históricas do fenômeno jurídico, dos seus institutos e dos seus instrumentos, devem se contrapor à tradicional historicidade pautada em proposições de continuidade, previsibilidade, formalismo e linearidade (WOLKMER, 1994).

\footnotetext{
* Doutoranda no Programa de Pós-Graduação em Direito da Universidade Federal do Pará (PPGD/UFPA) em regime de cotutela com a Université Paris 1 - Panthéon Sorbonne (École Doctorale de Droit de la Sorbonne). Mestre em Direito (PPGD/UFPA). Professora Substituta de Direito e Legislação da Universidade Federal Rural da Amazônia (UFRA/Campus Parauapebas). E-mail: analuisasrocha@gmail.com.
} 
Nesse sentido, as percepções sobre as diferentes relações entre pessoas e coisas, como "domínio", "posse" e "propriedade" devem ser analisadas de acordo com o contexto em que se inserem (PAES, 2018). Sendo o direito um produto histórico, as considerações sobre tempo e local em que foram pensados, formulados e colocados em prática são reflexões que devem ser postas em primeiro plano (STAUT JÚNIOR, 2009).

Essas questões devem ser consideradas pressupostos básicos para se pensar a história fundiária no Brasil, especialmente quando se focaliza nos diferentes modelos normativos que regulamentaram o acesso à terra, ou mais especificamente, o acesso à propriedade. No caso do século XIX, por exemplo, há que discutir essas concepções tendo em vista que sofreram "mudanças fundamentais na passagem do chamado ius commune para o direito liberal" (PAES, 2018, p. 42).

A análise do histórico fundiário brasileiro, que tradicionalmente na discussão agrarista se divide em quatros períodos - regime sesmarial, regime de posse, regime da Lei de Terras e período republicano (ROCHA et al., 2015) -, deve ter como fio condutor a noção de que a propriedade nesses diferentes momentos sofreu alterações e processos de continuidades/descontinuidades históricas (FONSECA, 2005). Logo, não houve um processo linear de "evolução histórica", mas antes a "convivência" simultânea de distintas noções que legitimavam o acesso à terra (BENATTI, 2003).

A forma com que se deu o processo de construção do direito de propriedade no Brasil mesclou concepções sociais e jurídicas pautadas no reconhecimento comunitário da titularidade de bens e nas relações que preconizavam a abstração de documentos dotados de determinados requisitos formais (PAES, 2018).

Assim, mediante pesquisa exploratória e abordagem histórico-jurídica, o presente artigo tem como objetivo apresentar elementos da construção histórica do direito de propriedade no Brasil, com foco específico nos regimes dos séculos XVI ao XIX. Na primeira seção são apresentadas discussões sobre o regime sesmarial e nas duas seções seguintes, discussões sobre o período Imperial e sobre a construção da propriedade moderna no Brasil.

\section{Regime Sesmarial}

É possível afirmar que antes da descoberta do Brasil, suas terras já eram objeto de disputas e conflitos. Portugueses e espanhóis possuíam ambiciosos projetos de colonização e 
exploração para as novas terras a serem conquistadas. Por conta dos Tratados de Alcaçovas (1479) e de Tordesilhas (1494) as terras brasileiras passaram a pertencer à Coroa Portuguesa, por direito de conquista. Daí a afirmação de que o direito brasileiro nasceu em Portugal.

Como consequência dessa divisão, para que os particulares pudessem ter acesso e exercer direitos sob a terra no Brasil, deveriam possuir o aval real. Não existiam terras sem donos, pois todas foram incorporadas ao patrimônio do rei. Assim, para acessá-las na colônia havia a necessidade do desmembramento das terras do domínio público real ao particular ${ }^{\dagger}$ (TRECCANI, 2001).

As normas reguladoras do acesso à terra no Brasil Colônia não foram resultado de um processo próprio aplicado à novas áreas. Houve, na verdade, transposição de institutos jurídicos já existentes em Portugal que regulavam o acesso à propriedade (SILVA, 2008). Em 1531, implantou-se no Brasil o sistema sesmarial. Esse sistema foi criado em 1375 através da Lei de Sesmaria, durante o reinado de Dom Fernando.

Nos primeiros trintas anos de Brasil Colônia não houve, de plano, interesse da Coroa Portuguesa no projeto de colonização. Foram as ameaças de invasão e o objetivo de defesa do território que fomentaram a ocupação e a colonização efetiva por parte da metrópole.

Durante essas três décadas, a colônia foi dividida administrativamente em capitanias. Quanto ao aspecto fundiário, o regime de capitanias deixou poucos reflexos na estrutura fundiária do país (COSTA PORTO, 1965), posto que os donatários que recebiam as faixas de terras possuíam apenas poderes de caráter administrativo e de gestão. No que tange ao aspecto patrimonial, o domínio das terras continuava com a Coroa Portuguesa, quadro que só se altera com a instauração do regime sesmarial.

A essência da lei lusitana estava na necessidade de combater o êxodo rural incentivando a agricultura. Na segunda metade do século XIV, Portugal vivenciava um contexto de lutas internas, invasões estrangeiras e guerras que provocaram uma forte crise de abastecimento. O objetivo com a Lei de Sesmaria era promover a cultura do solo (COSTA PORTO, 1965).

\footnotetext{
${ }^{\dagger}$ De acordo com Treccani (2001, p. 28): “[...] as terras eram assim originalmente públicas e, até hoje, elas podem ser consideradas propriedade de particulares só se estes comprovarem que as receberam a justo título. Esta observação histórica, de aparente pouco valor prático, tem, ao contrário, um enorme valor jurídico [...]". O valor jurídico indicado pelo autor é importante para a construção e análise das origens fundiárias em cadeias dominiais de imóveis. Do ponto de vista jurisprudencial, há no âmbito do Superior Tribunal de Justiça em ações de usucapião (STJ) a tese de que a ausência de transcrição no registro imobiliário não gera a presunção de que as terras são devolutas, cabendo ao Estado o ônus da prova (SILVA, 2018).
} 
O modelo sesmarial foi incorporado às Ordenações do Reino: as Afonsinas (1446), as Manuelinas (1511) e as Filipinas (1603). Nas Ordenações Filipinas as sesmarias são definidas como "dadas de terras, casais ou pardieiros que foram ou são de alguns senhorios e que já em outro tempo foram lavradas e aproveitadas e agora o não são". Exigia-se aproveitamento do solo por parte de seus donos, sob pena de confisco (COSTA PORTO, 1965), mas quando o regime foi suplantando ao Brasil, na prática colonial esse princípio não se implementou.

A partir de 1531, com a aplicação dessas regras, a concessão de cartas de sesmarias no Brasil colônia fez surgir a chamada propriedade sesmarial. Benatti (2003) ressalta que o conceito de propriedade sesmarial reflete uma concepção sociológica e considera a realidade social na discussão do significado da propriedade de terras no período histórico específico em que se aplicou o regime. Assim, para o autor as cartas eram como concessões reais gratuitas translativas de propriedade.

As Ordenações portuguesas, de maneira geral, exigiam o cumprimento de uma série de cláusulas a serem obedecidas pelos sesmeiros, pois as concessões não eram incondicionadas. Dentre elas, podem ser citadas as obrigações de aproveitamento, cultivo e demarcação. Sob o aspecto estritamente jurídico, por serem condicionadas e sujeitas ao retorno das terras ao domínio real, discute-se se as cartas refletiriam um regime enfitêutico (TRECCANI, 2001).

Para Fonseca (2005), por exemplo, apesar de o projeto colonial ser fruto de anseios mercantilistas, a sistemática sesmarial foi respaldada e construída em parâmetros medievais de propriedade, considerando que o sistema foi formulado no séc. XIV. Nesse viés, entendese que no regime sesmarial aplicado ao Brasil colônia havia a premissa jurídica de que a Coroa Portuguesa se mantinha como proprietária das terras.

Na Idade Média, que configura o pré-moderno europeu, as relações entre pessoas e coisas eram marcadas por um vigoroso princípio de efetividade, vislumbrando-se mais as relações possessórias e a efetividade econômica do bem, em suas múltiplas possibilidades de uso (GROSSI, 1992). Nesse contexto, não existia nessas relações a figura de um titular de direito exclusivo. Havia, na verdade, um primado da coisa que poderia responder a diferentes usos e demandas, sem um sujeito dominador único (FONSECA, 2005).

Para Costa Porto (1965), uma vez que as cláusulas fossem cumpridas, os sesmeiros adquiriam o domínio pleno do solo, com efeitos reconhecidos desde o momento de concessão da carta. 
Apesar dessa discussão, do ponto de vista prático, com a concessão de sesmarias as terras foram incorporadas ao patrimônio dos seus detentores (TRECCANI, 2001). Benatti (2003) defende que se enquadram no conceito de propriedade sesmarial, em seu sentido sociológico, tanto aquela confirmada pelo rei, quanto à concedida pelos representantes da Coroa na colônia. A diferença existia em razão do procedimento para se requerer a sesmaria: a carta de data e sesmaria representava a concessão da terra ao sesmeiro que deveria cumprir as condições estabelecidas na legislação portuguesa aplicada à Colônia confirmação real, representava o título definitivo (BENATTI, 2003).

Os maiores beneficiários das concessões foram homens de muitas posses, ricos e influentes - os "amigos do rei” -, pois apenas eles possuíam condições econômicas para desenvolver o projeto de ocupação da colônia (BENATTI, 2003). Mesmo com as condições impostas pelas Ordenações portuguesas, o desrespeito era frequente. Para além da doação de sesmarias, muitas terras foram ocupadas independentemente do prévio reconhecimento oficial (FONSECA, 2005). Durante os primeiros séculos de colonização havia poucos moradores e muitas terras motivando o descumprimento das condições impostas nas concessões de sesmarias.

Diante da fartura de terras a serem ocupadas e a dificuldade de acesso à Coroa Portuguesa, ao lado da propriedade "oficial" consolidou-se segundo Benatti (2003) a propriedade senhorial, marcada pela apropriação privada das terras públicas, representando verdadeira contradição com as normas emanadas de Portugal. O costume da colônia acabou por conceder o status de propriedade privada rural a essa transferência não oficial dos bens públicos para o domínio privado.

Em relação à propriedade senhorial uma série de instrumentos e condições sociais, econômicas e jurídicas a confirmavam e a mantinham, entre eles o costume local. Para Benatti (2003, p. 37), durante o período colonial existiu no Brasil uma disputa e concorrência jurídica no "monopólio do direito de dizer o direito". A contradição entre as normas lusitanas e o costume brasileiro representava disputa pelo controle jurídico e do direito sobres as terras entre a metrópole e a colônia ${ }^{\S}$.

\footnotetext{
* Embora o sistema estivesse disposto nas Ordenações Portuguesas, foram normas esparsas (forais, decretos, alvarás e cartas régias) que regularam o procedimento de concessão de terras e os direitos e deveres dos sesmeiros ao longo do período colonial (BENATTI, 2003).

§ Isso é evidente no fato de que a aristocracia colonial era favorecida e poderosa em âmbito local, mas sem qualquer força e pressão frente ao poder real. As autoridades locais, por exemplo, reconheceram a prescrição
} 
Nas relações entre o Império ultramarino português e suas colônias, Antônio Manuel Hespanha (2001) defende que a visão dominante de uma "centralidade" da Coroa com as suas instituições, o seu direito e os seus oficiais deve ser revisada. Essa noção permeou a historiografia por refletir preconceitos enraizados acerca da relação colonial, além de expressar a visão do colonizador que não admitiria o papel dessas forças periféricas coloniais $^{* *}$.

Vale ressaltar também que a estrutura burocrática portuguesa era marcada por uma teia de normatividades, o que representava um contexto de sobreposição de ordens normativas e jurisdições nas colônias. No período colonial brasileiro, o que se manejava em termos administrativos era a estrutura normativa do direito comum (ius commune). Nesse modelo, ainda não se vislumbrava a noção de direito propriedade individual, absoluto e exclusivo, e superior a todos os outros direitos reais, como nos moldes liberais que se consolidaram no Brasil a partir do final do século XIX (PAES, 2018).

O domínio, na lógica do direito comum, refletia uma faculdade de uso abrangendo uma série de possibilidades de gozo sobre as coisas, em razão de suas múltiplas utilidades. Era sobre essas utilidades que recaía o domínio, e não sobre a coisa em si. Não existia hierarquia entre os diferentes domínios que poderiam incidir sobre a mesma coisa e nem equivalência direta entre as noções de domínio e de propriedade. Em verdade, na estrutura do direito comum, o domínio e uso efetivo da coisa eram equivalentes. Em situações de conflitos, por exemplo, prevalecia o domínio de quem estivesse usando a coisa, isto é, exercendo posse sobre ela (PAES, 2018).

Tendo em vista essa discussão, pode-se afirmar que para além do sesmarialismo colonial (COSTA PORTO, 1965) e as suas imensas concessões de áreas ao mesmo sesmeiro e o alargamento dos domínios por aquisição derivada dos imóveis privados (doação, compra e venda e herança), o apossamento de terras públicas - a propriedade senhorial - contribuíram para a formação do latifúndio no Brasil Colônia (BENATTI, 2003).

aquisitiva e os documentos privados de transferências de terra foram confirmados e legalizados (BENATTI, 2003).

*** Para o autor (HESPANHA, 2001), a ideia de um colonialismo absoluto e centralizado na expansão do Império português e uma rígida oposição entre metrópole e colônia devem então ser relativizadas, pelo menos até a década de 70 do século XVIII, quando as intenções colonizadoras pós-revolucionárias da Coroa Portuguesa foram mais claras. 
É importante frisar que o regime sesmarial e o regime de posse conviveram lado a lado, inclusive, os próprios sesmeiros não respeitavam as cartas de sesmarias ${ }^{\dagger \dagger}$, ampliando suas áreas além dos limites concedidos. Ora, quanto mais terras, maior a produção agrícola e maior o prestígio político. Era o poderio econômico, a influência e a violência contra pequenos ocupantes que legitimavam o apossamento primário de terras públicas.

Em relação a esse processo entre o regime oficial de aquisição de terras com o aval da Coroa e o regime pautado nos costumes da colônia e no apossamento das terras, destaca Holston (2013, p. 167):

Durante o período colonial, a ocupação de terras tinha um estatuto jurídico ambíguo. As posses eram ilegais porque violavam o estipulado de que a terra só podia ser adquirida através de uma concessão real. Contudo, costumavam ser reconhecidas como legítimas se fossem ativamente cultivadas por longo tempo com uma produção contínua e evidente. Assim, os posseiros produtivos dispunham de certos direitos consuetudinários.

Ao se falar em apossamento pode-se ter a ideia de que o acesso às terras públicas favorecia a todos, entre eles, indígenas, pequenos e médios posseiros. Entretanto, o apossamento de terras públicas e a consequente aquisição de domínio favoreciam apenas aos grandes proprietários. Era apenas as elites agrárias quem podiam manter o reconhecimento de suas posses o que funcionava como estímulo para que mais e mais terras públicas fossem apossadas para o aumento de propriedades (HOLSTON, 2013).

Embora houvesse abundância de terras, elas não estavam disponíveis para todos, mas apenas para aqueles que possuíam condições suficientes de sustentar o seu domínio (BENATTI, 2003). Seja a distribuição oficial, seja o apossamento, no período colonial apenas as classes dominantes aristocráticas, escravistas e comerciais consagraram-se com direitos de propriedade outorgados. Aos livres e pobres restou uma persistente situação de desigualdade, desfavorecimento, ilegalidade e violência (HOLSTON, 2013).

A consolidação da grande propriedade fundiária durante o período colonial se deu em razão da falta de regularização, incorporação e destruição dos recursos florestais e da mão de obra escrava, ou seja, adotou-se uma lógica de utilização predatória dos recursos naturais, sempre se explorando a mão de obra escrava e submetendo os pequenos posseiros ao cabresto dos senhores de terra (BENATTI, 2003). ${ }^{\dagger \dagger}$ Inúmeras cartas de sesmarias, além de desrespeitarem os limites demarcados, não foram sequer confirmadas
pela Coroa Portuguesa devido ao descumprimento das cláusulas (BENATTI, 2003). 


\section{Regime da Lei de Terras de 1850}

Em 1822, mediante a Resolução $n^{\circ} .76$ de 17 de julho, pouco antes da Independência do Brasil, o sistema de sesmarias foi suspenso e até a edição da Lei $\mathrm{n}^{\circ}$. 601, de 18 de setembro de 1850, conhecida como Lei de Terras, o Império Brasileiro não possuía qualquer legis lação regulamentando o regime jurídico de propriedade de terras. Não havia também legislações brasileiras dispondo sobre as questões civis, o que justificou a permanência e a aplicação do arcabouço jurídico português ao Brasil Independente ${ }^{*}$.

Com a Independência, a legislação herdada de Portugal continuou a ser aplicada ${ }^{\S \S}$, sendo manejada para responder às demandas das tradições brasileiras e da cultura jurídica em gênese, além de se moldar aos interesses das elites agrárias brasileiras. A antiga metrópole, ao contrário, passou a sofrer forte influência do pensamento liberal e dos princípios do Código Civil Napoleônico de 1804.

Sobre o quadro jurídico instaurado após a Independência, Ricardo Fonseca (2006, p. 66) assevera:

A coexistência de uma Monarquia Constitucional com a escravidão, ou então da escravidão com um rol de liberdades individuais copiadas da Constituição Francesa de 1791, demonstram como a incidência dos princípios jurídicos no Brasil caracterizou-se, desde o início do Império, por uma "flexibilidade" conveniente e por uma "adaptabilidade" oportuna.

A Constituição Brasileira de 1824, a primeira da história constitucional do país, previa em seu artigo 179, $\S 22$, que o direito de propriedade era garantido em sua plenitude. Sem uma legislação agrária para regulamentar ou limitar o acesso, o direito de propriedade era interpretado como absoluto e intangível. Quanto à mão de obra, o referido postulado de

\footnotetext{
\# As Ordenações Filipinas e seu regramento civil, por exemplo, possuíam validade jurídica no país até o advento do Código Civil de 1916. A Lei de 20 de outubro de 1823 assim dispunha: "Art. 1". As Ordenações, Leis, Regimentos, Alvarás, Decretos, e Resoluções promulgadas pelos Reis de Portugal, e pelas quaes o Brazil se governava até o dia 25 de Abril de 1821, em que Sua Magestade Fidelissima, actual Rei de Portugal, e Algarves, se ausentou desta Côrte; e todas as que foram promulgadas daquella data em diante pelo Senhor D. Pedro de Alcantara, como Regente do Brazil, em quanto Reino, e como Imperador Constitucional delle, desde que se erigiu em Imperio, ficam em inteiro vigor na pare, em que não tiverem sido revogadas, para por ellas se regularem os negocios do interior deste Imperio, emquanto se não organizar um novo Codigo, ou não forem especialmente alteradas".

\$§ É necessário salientar que esse processo de aplicação da legislação portuguesa herdada pelo Brasil após a Independência, especialmente quanto ao aspecto civil, não se deu de forma contínua, pois houve rupturas e descontinuidades. No que tange à propriedade, por exemplo, a Lei de Terras de 1850 trouxe regulamentação específica. Sobre o assunto, explica Gustavo Silveira Siqueira (2017, p. 166): “[...] o uso das Ordenações existia, mas ele não ocorria sozinho, muitos artigos estavam revogados por lei, pela 'consciência jurídica', ou em desuso. Dizer que as Ordenações regulavam toda a vida civil antes do Código de 1916 pode ser temerário. Elas conviviam em conjunto com outros estatutos legais".
} 
“caráter liberal", reforçou o regime de escravidão e a "propriedade" sobre os escravos. Quanto ao aspecto fundiário, sem uma regulamentação específica e quase três décadas de vazio legislativo vivenciou-se o "Período Áureo da Posse"(MATTOS NETO, 1988) durante o qual a simples ocupação e a posse primária da terra já garantiam o direito de propriedade, sem quaisquer formalidades.

A partir desse marco constitucional imperial passou a existir no país um verdadeiro paradoxo: de um lado um mundo histórico e real, do outro o mundo do direito formal. Isto porque o ordenamento constitucional afirmava o direito de propriedade a partir dos moldes modernos que se consolidavam na Europa (FONSECA, 2005) com a Declaração dos Direitos do Homem e do Cidadão da Revolução Francesa (1789) e com o Código Civil napoleônico (1804).

Entretanto, os moldes jurídicos "modernos" de uma propriedade plena e exclusiva conviviam, no século XIX, com a realidade de um país cuja economia dependia da mão-deobra escrava e cuja terra se adquiria por práticas de simples ocupação. Havia, assim, uma presença meramente formal do sujeito livre e proprietário e na prática uma propriedade imobiliária regida por institutos coloniais e por ocupações (FONSECA, 2005).

Marianna Dias Paes (PAES, 2018) destaca na primeira metade do século XIX, o direito brasileiro, especificamente quanto às relações entre pessoas e coisas, ainda estava baseado no ius commune, prevalecendo interpretações que privilegiavam o uso efetivo da coisa e a posse como garantia de direito ${ }^{* * *}$. Assim, a relação de fato preponderava frente a um título individual de propriedade.

Foi a discussão claramente dependente entre mão-de-obra escrava e propriedade de terras que impulsionou no país ao longo do século XIX a consolidação da "propriedade moderna". Com o regime de escravidão dando sinais de progressivo enfraquecimento, seja pelas sanções impostas pela Inglaterra contra o tráfico negreiro, seja pelos setores políticos que passaram a condenar o regime e o modelo "atrasado" de produção agrícola, as discussões sobre a regulamentação da propriedade ganharam espaço.

\footnotetext{
**** $\mathrm{O}$ foco no uso efetivo da coisa e não no título refletia as práticas jurídicas da época (primeira metade do séc. XIX), construída nos tribunais e no dia a dia dos procedimentos imperiais. Tratava-se de percepção "socialmente construída" (PAES, 2018, p. 44) e não integralmente decorrentes de doutrinas europeias diretamente aplicadas ao direito brasileiro.
} 
Para Fonseca (2005, p. 107/108): “[...] as questões da mão de obra e da propriedade, em meados do século XIX, constituíam um nó a ser desatado pelo jovem Estado Brasileiro na pavimentação de sua modernidade".

Nesse mesmo sentido, Laura Beck Varela (2005, p. 126) destaca:

\begin{abstract}
A necessidade premente de organizar o direito à propriedade privada da terra, direito natural do homem, conforme os princípios do moderno Direito público universal, está essencialmente conjugada com a constituição de uma "nação" independente. O discurso progressista do momento da independência articula os elementos da emancipação de jure do Brasil-colônia, o fim da escravidão, a organização da propriedade privada da terra e o fomento da agricultura. Pressupostos, elementos em necessária correlação, componentes de um projeto político, de um ideário liberal que se esboçava.
\end{abstract}

Com o advento da Lei de Terras de 1850 começou-se a estabelecer o que hoje se entende por propriedade. Nesse período, reinava a indefinição fundiária, pois o Império não conhecia suas terras, muito menos as terras que estavam nas mãos dos particulares (MACHADO, 2011).

O propósito básico da norma era acabar com as formas tradicionais de aquisição, sobretudo a posse, além de regularizar as situações possessórias anteriores (decorrentes de doações de sesmarias cujas condições não foram atendidas ou apossamentos), com o cumprimento de certos requisitos (FONSECA, 2005). A norma estabeleceu também critérios para a colonização das terras por colonos estrangeiros, bem como a forma de financiamento da vinda dos colonos.

Em vez de ser um instrumento de reforma social e ruptura com o sistema de concentração de propriedade, a legislação em comento representou a consolidação das situações jurídicas anteriores. A Lei de Terras valorizou a cultura e a morada habitual, possibilitando assim, a revalidação de sesmarias e concessões reais não confirmadas, bem como legitimou as ocupações anteriores à lei não fundadas em qualquer título ${ }^{\dagger \dagger}$.

\footnotetext{
†† Art. $4^{\circ}$ Serão revalidadas as sesmarias, ou outras concessões do Governo Geral ou Provincial, que se acharem cultivadas, ou com principios de cultura, e morada habitual do respectivo sesmeiro ou concessionario, ou do quem os represente, embora não tenha sido cumprida qualquer das outras condições, com que foram concedidas. Art. $5^{\circ}$ Serão legitimadas as posses mansas e pacificas, adquiridas por occupação primaria, ou havidas do primeiro occupante, que se acharem cultivadas, ou com principio de cultura, e morada, habitual do respectivo posseiro, ou de quem o represente, guardadas as regras seguintes: [...].
} 
Além disso, a lei retirou a possibilidade de apropriação de terras devolutas de forma primária, instituindo a compra como único meio de aquisição. Aqueles que ocupassem terras de devolutas seriam a partir daquele momento, penalizados ${ }^{\text {tht }}$.

Optou-se pelo critério da exclusão para definir as terras devolutas pertencentes ao Império. Dispunha o art. $3^{\circ}$ da Lei de Terras:

São terras devolutas: $\S 1^{\circ}$ As que não se acharem applicadas a algum uso publico nacional, provincial, ou municipal; $\S 2^{\circ}$ As que não se acharem no dominio particular por qualquer titulo legitimo, nem forem havidas por sesmarias e outras concessões do Governo Geral ou Provincial, não incursas em commisso por falta do cumprimento das condições de medição, confirmação e cultura; $\S 3^{\circ}$ As que não se acharem dadas por sesmarias, ou outras concessões do Governo, que, apezar de incursas em commisso, forem revalidadas por esta Lei; $\S 4^{\circ}$ As que não se acharem occupadas por posses, que, apezar de não se fundarem em titulo legal, forem legitimadas por esta Lei.

Ao estabelecer um novo regime jurídico para aquisição da propriedade de terras, buscando delinear quais terras seriam públicas e quais terras seriam privadas, com procedimentos específicos de medição e demarcação, Ricardo Fonseca (2005) afirma que passou a vigorar no país a noção de propriedade com elementos modernos, com um proprietário individual definido, seja ele público ou particular, que passa a exercer poderes exclusivos sobre o imóvel.

Sob esse aspecto, e levando em consideração a realidade social do Brasil Colônia e Brasil Império, as definições sociológicas de propriedade elencadas por Benatti (2003) - a sesmarial, a senhorial e a moderna -, já representavam segundo o autor, modelos absolutos e individuais de exercício de poder sobre os imóveis, pelas razões históricas e aplicações próprias do regime no país.

É possível apontar que a divergência doutrinária resulta do fato de que Fonseca (2005) considera o regime sesmarial como um modelo de domínio compartilhado, em razão de enxergar a Coroa Portuguesa como detentora de todo o patrimônio fundiário da colônia, mesmo quando havia concessão e confirmação de sesmarias. Para o autor, por se tratar de um sistema formulado originalmente no século XIV, a mentalidade jurídica reinante nas sesmarias era a medieval em que o domínio das terras era compartilhado.

Ligia Osório Silva (2008, p. 88) adota o mesmo posicionamento indicando que “[...] o direito à propriedade não era absoluto, no sentido romano do termo, mesmo para os sesmeiros

$\$+$ Art. $2^{\circ}$ Os que se apossarem de terras devolutas ou de alheias, e nellas derribarem mattos ou lhes puzerem fogo, serão obrigados a despejo, com perda de bemfeitorias, e de mais soffrerão a pena de dous a seis mezes do prisão e multa de $100 \$$, além da satisfação do damno causado [...]. 
que haviam cumprido as condições das doações, pois a condicionalidade estipulada pelas Ordenações nunca foi revogada". Entretanto, a autora destaca que a utilização da expressão "proprietários de terras", por comodidade designa todos os ocupantes de terras sem distinções, considerando a realidade colonial e do início do Império.

Em que pese a discussão teórica, o regime jurídico estabelecido na Lei de Terras colocou a propriedade imobiliária no mercado como objeto de troca (FONSECA, 2005), como um produto mercantil (BENATTI, 2003). Inclusive, como já apontado, criminalizou-se o ato de ocupar terras, públicas ou particulares, sem a licença do dono ${ }^{\S \S \S}$.

Embora houvesse previsões na Lei de Terras determinando a medição e a demarcação das propriedades $^{* * * *}$, na prática os apossamentos primários continuaram. O Poder Público não possuía condições de fiscalizar, planejar e controlar o processo de aquisição de terras. A principal legislação agrária da monarquia não conseguiu alterar o caótico quadro fundiário em que se encontrava o país, pois nem as terras devolutas foram demarcadas e nem as particulares legalizadas ${ }^{\dagger \dagger \dagger}$.

Do ponto de vista estritamente jurídico, Fonseca (2005) defende que a Lei de Terras refletiu a transformação do conceito de propriedade, com influência das concepções "modernas" francesa e americana, de um direito de propriedade absoluto e individual. Para o autor, em que pese as análises sobre a ineficiência prática dos instrumentos da Lei de Terras, ou ainda, as discussões sobre os efeitos problemáticos que ela causou, o fato é que antes de 1850, a concepção jurídica de propriedade no Brasil poderia ser considerada "pré-moderna" (FONSECA, 2005, p. 111).

O autor deixa claro, entretanto, que sua tese sobre a "modernidade" se aplica ao elemento jurídico, enquanto legislação "modernizante". Esse recorte é importante, pois destaca que para os escravos, pobres e trabalhadores em geral a mudança no "pensamento

\footnotetext{
$\S \S \S$ Quando vigorava o regime da escravidão no Brasil, era o número de escravos e não a terra que garantia poder econômico e riqueza, porém quando se optou aos poucos pelo trabalho livre a terra tornou-se uma mercadoria lucrativa, ou seja, quando os homens iniciaram seu processo de libertação, fechou-se o livre acesso à terra (TRECCANI, 2001).

***** Art. $7^{\circ} \mathrm{O}$ Governo marcará os prazos dentro dos quaes deverão ser medidas as terras adquiridas por posses ou por sesmarias, ou outras concessões, que estejam por medir, assim como designará e instruirá as pessoas que devam fazer a medição [...].

††† Márcia Motta (2002) destaca que os Relatórios do Ministério da Agricultura dos anos 1870 apresentam informações sobre a sistemática continuidade do processo de invasão, usurpação e devastação das terras públicas, mesmo sob a égide da Lei de Terras.
} 
jurídico" não alterou o quadro de dominação, exploração e concentração de terras ${ }^{\text {t+ł }}$, embora o sistema jurídico-fundiário fosse alcunhado de "moderno" (FONSECA, 2005, p. 112).

Soma-se à questão fundiária, o fato de a Lei de Terras estar relacionada com a discussão de mão-de-obra no país. "Modernizar" o acesso à propriedade imobiliária estava diretamente ligado à necessidade de modernizar a economia e a mão-de-obra com a inserção do trabalho livre e assalariado nas lavouras (FONSECA, 2005). Porém, no que tange a medidas sociais e de acesso à cidadania e à propriedade dos que compunham o contingente de trabalho nas lavouras não houve pauta ${ }^{\S \S \S}$.

\section{Instrumentos de consolidação da propriedade moderna}

É a partir do final do século XIX, com a implantação do sistema hipotecário, que começam a ser visualizados os elementos que instrumentalizariam por completo, a partir dos anos de 1930 a propriedade moderna (BENATTI, 2003). Em que pese a ausência de uma legislação civil codificada ${ }^{* * * * *}$ e a permanência das antigas normas da metrópole ainda em vigor, especificamente quanto à propriedade, a Lei de Terras de 1850 e a Lei Hipotecária de 1864 romperam com a antiga legislação, conferindo-a caráter liberal (FONSECA, 2006).

No decreto $\mathrm{n}^{\mathrm{o}}$. 1.318, de 30 de janeiro de 1854, regulamentador da Lei de Terras, houve uma primeira tentativa de cadastrar as propriedades privadas e discriminá-las das terras públicas. Criou-se o chamado Registro Paroquial ou do Vigário ${ }^{\dagger \dagger \dagger \dagger}$. Tratava-se de um instrumento com caráter meramente estatístico que determinava que os possuidores de terras,

\footnotetext{
Mat Márcia Motta ressalta que apesar de um quadro de violência e desmandos por parte de grandes proprietários ao longo do século XIX, não deve ser descartada a possibilidade de contestação dos pequenos posseiros que justificavam a legitimidade de sua ocupação a partir do argumento de antiguidade. Não se buscava, nesse argumento, o aspecto patrimonial, mas sim, o direito de liberdade efetiva sobre a terra e de reprodução da unidade familiar sem dependência de um senhor. Segundo a autora, essas experiências devem ser consideradas com vistas à recuperação da historicidade dos movimentos sociais rurais do Brasil (MOTTA, 2006).

$\$ \$ \S \mathrm{O}$ acesso restrito à propriedade da terra forçou, desde o período colonial, que grande parte dos brasileiros morassem ilegalmente, sendo a ilegalidade quase uma norma nos assentamentos urbanos e rurais no país. A Lei de Terras de 1850, a primeira legislação fundiária nacional, apontada como a gênese do mercado de terras brasileiro pode ser caracterizada como uma lei de desigualdade e injustiça, pois a democratização do acesso à propriedade não foi opção naquele momento (HOSLTON, 2006).

Ricardo Fonseca (2006) destaca que a cultura jurídica brasileira ao longo do século XIX teve como traço marcante sua função conservadora, conduzindo o país na contramão da tendência codificadora da legislação civil.

$\dagger_{\dagger \dagger \dagger}$ Na então Província do Pará por exemplo, segundo dados do Relatório do Ministério da Agricultura de 1860, foram efetuados o maior número de registros paroquiais (MUNIZ, 1904), instrumento cadastral criado pela Lei $n^{\circ} .601 / 1850$.
} 
a qualquer título, deveriam registrá-las ${ }^{4+\ldots}$ perante os Párocos nas Freguesias ${ }^{\S \S \S \S}$ competentes.

No que tange às práticas sociais de apropriação de terras no Brasil ao longo do século XIX e a obrigatoriedade do Registro Paroquial, destaca Manuela Pedroza (2016, p. 16/17):

O registro paroquial de terras expressou bem a distância entre a 'vontade da lei' que queria separar de um lado, proprietários legítimos e exclusivos das terras e, de outro, terras devolutas, isto é, sem dono - e o exercício cotidiano dos direitos de propriedade no Brasil daqueles tempos. Na vida real, homens e mulheres exercitavam diferentes formas de acesso à terra, com diversas possibilidades de normatização, baseados em diferentes costumes, que praticamente não podiam ser 'encaixados' nos termos binários - proprietários ou não - previstos pela Lei.

É possível ainda afirmar que esse instrumento não surtiu os efeitos esperados ante a inexistência de mecanismos para exigi-lo e, principalmente, por não se tratar de um levantamento idôneo, já que eram os próprios proprietários ou possuidores que declaravam suas terras. Além disso, é de se considerar também, à desconfiança em relação à Lei de Terras e à nova realidade jurídica por ela estabelecida (FERREIRA, 2012).

$\mathrm{Na}$ esteira do processo de mercantilização das terras públicas no Brasil e da absolutização da propriedade fundiária dispostas na Lei de Terras, através da Lei $\mathrm{n}^{\circ}$. 1.237, de 24 de setembro de 1864, criou-se o Registro Geral, voltado sobretudo para a disciplina das hipotecas e do seu registro, instrumentos essenciais à proteção do crédito:

É a hipoteca um dos principais institutos jurídicos em prol da circulação da riqueza, na medida em que possibilita constituir a propriedade imobiliária garantia de crédito nas transações. O registro, por sua vez, confere segurança a tais transações (VARELA, 2005, p. 174).

A referida lei e o seu decreto regulamentador (Decreto $n^{\circ} .3453$, de 26 de abril de 1865), visavam substituir a transmissão da propriedade imobiliária da tradição pela transcrição em registro público. O objetivo era acabar com a insegurança jurídica sobre os imóveis em relação às hipotecas ocultas e outros ônus que sobre eles recaíam. Antes, para a transferência do domínio entre particulares bastava um contrato particular e a simples tradição do imóvel para a aquisição do domínio.

+m+ Art. 91. Todos os possuidores de terras, qualquer que seja o titulo de sua propriedade, ou possessão, são obrigados a fazer registrar as terras, que possuirem, dentro dos prazos marcados pelo presente Regulamento, os quaes se começarão a contar, na Côrte, e Provincia do Rio de Janeiro, da data fixada pelo Ministro e Secretario d'Estado dos Negocios do Imperio, e nas Provincias, da fixada pelo respectivo Presidente.

§§§§ Art. 97. Os Vigarios de cada huma das Freguezias do Imperio são os encarregados de receber as declarações para o registro das terras, e os incumbidos de proceder á esse registro dentro de suas Freguezias, fazendo-o por si, ou por escreventes, que poderão nomear, e ter sob sua responsabilidade. 
A nova legislação inovou no ordenamento jurídico brasileiro ao estabelecer a transcrição e o registro, considerados "pedras fundamentais" do novo modelo proprietário. O art. $7^{\circ}$ da referida lei determinava o registro não abrangeria somente as hipotecas, como também a transcrição dos títulos de transmissão de imóveis suscetíveis de hipoteca e de criação de ônus reais. Assim, instituiu-se um "verdadeiro sistema de publicidade, condição essencial à natureza erga omens dos direitos reais (VARELA, 2005, p. 179).

Importante frisar que, a publicidade registral presente na Lei Hipotecária de 1864, não possuía o caráter obrigatório como no atual sistema registral de imóveis. Ela tinha o efeito de tão somente garantir a oponibilidade perante terceiros, conforme vontade das partes (VARELA, 2005).

A lei, sem instituir um sistema registral completo, trouxe avanços para a formalização do registro (DINIZ, 2014), conferindo segurança quanto às informações do proprietário e os possíveis ônus existentes sobre a propriedade, mas pela ausência de mecanismos coercitivos e pelos próprios costumes brasileiros, a tradição e as práticas de simples compra e venda continuaram a ser utilizada como instrumento translativo de propriedade (BENATTI, 2003).

Ainda em 1890, o Decreto $\mathrm{n}^{\circ}$ 451-B criou o Registro Imobiliário Torrens. Mediante sentença transitada em julgado, o registro Torrens conferiria um direito incontestável, garantindo maior segurança jurídica para quem possuísse o título da matrícula ${ }^{* * * * * *}$. Constariam no registro a indicação do assentamento do imóvel, com todas as suas especificações físicas e jurídicas. A intenção do oficial do Registro Torrens era sanear as inúmeras posses fundadas em títulos sem força dominial. Com a matrícula, afastar-se-ia qualquer dúvida sobre o domínio do imóvel (TRECCANI, 2001).

Em que pese essas inovações, é válido apresentar a crítica formulada por Pedro Parda Rodrigues (2014) quanto às generalizações de que a Lei de Terras, ao lado, sobretudo da Lei Hipotecária, originou a propriedade privada no Brasil. O autor demonstra em sua pesquisa a necessária relativização dessas afirmações que superestimaram a utilização em larga escala dessas normas em todo território nacional. Não se nega a sua importância, mas o autor orienta a relativização, especialmente quando se consideram fatores locais ${ }^{\dagger \dagger \dagger \dagger \dagger}$.

\footnotetext{
${ }^{* * * * * * *}$ Esse é o termo utilizado atualmente pela Lei de Registros Públicos (Lei $\mathrm{n}^{\circ}$. 6.015/73) para designar os assentos dos imóveis nos livros de registro, mas desde 1890 a legislação já utilizava essa denominação, no caso de Registro Torres.

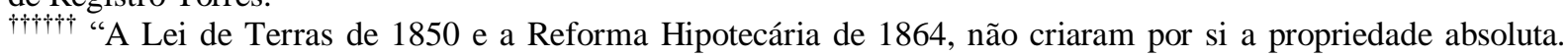
[...]Esta transformação talvez tenha ocorrido mais pela via da informalidade e nas brechas de legislação do que por efeito imediato destas normas jurídicas. Provavelmente, estas normas tiveram seu papel em um processo de
} 
A consolidação do sistema registral brasileiro se deu com o Código Civil de 1916 (Lei $n^{o}$. 3.071, de 01 de janeiro de 1916). A norma transformou o Registro Geral, então existente, em Registro de Imóveis e o tornou uma instituição pública com a função de transmissão de domínio, pois agora era considerado um dos meios aquisitivos de propriedade (DINIZ, 2014). Acrescentou-se ao sistema registral brasileiro a presunção de domínio valorizando e incentivando assim, a transcrição: o art. 859 dispôs que a transcrição gerava a presunção de domínio em favor de seu titular.

O Decreto $\mathrm{n}^{\circ}$. 18.542, de 24 de dezembro de 1928, que regulamentou os serviços de registros públicos, passou a exigir a transcrição da aquisição de propriedade em escrituras públicas para que os atos de transmissão operassem seus efeitos contra terceiros, sendo assim, sem o cumprimento dos requisitos, o adquirente do imóvel seria considerado um mero posseiro: "legalmente nada impede a quem continua com o domínio de alienar ou constituir um ônus real na propriedade, já que o imóvel continua a pertencer ao patrimônio do proprietário alienante e fica sujeito a sua dívida" (BENATTI, 2003, p. 91).

Ao lado da presunção de domínio disposta no Código Civil de 1916, a previsão do registro público para o reconhecimento do direito de propriedade perante terceiros consolidou os instrumentos da propriedade moderna (BENATTI, 2003), isto é, a propriedade pautada na demarcação e no registro como condições essenciais para a validade da transferência do patrimônio público para o particular.

Benatti (2003, p. 96) explica que após a implantação do sistema registral e da necessidade de transcrição dos títulos de terra emitidos pelo Poder Público em favor dos particulares, depois de quatro séculos de ocupação, somente com a legislação adotada em 1928, é que se tornou possível falar em cadeia dominial dos imóveis rurais e em uma possível organização cadastral.

\section{Considerações finais}

transformação incompleta, mas a mudança aconteceu mais através da ação dos agentes sociais interessados em sacralizar seus direitos sobre a propriedade em querelas judiciais do que por resultado de uma lei ou outra. [...] São necessários estudos sobre a particularidade dos conflitos de cada localidade para melhor entendermos essas transformações sociais. E estes estudos não podem se reduzir meramente aos dados quantitativos. Não basta perceber o crescimento do número de alienações. Faz-se necessário pensar como essas transmissões eram realizadas. Os imóveis alienados possuíam limites determinados? A formalidade da qual a operação de compra e venda dependia era a tradição (, ou seja, a entrega da posse da coisa) ou a matrícula do título em um registro público? Esta formalidade era de fato seguida no cotidiano? Era considerada prova dominial? Os bens alienados foram matriculados de forma individualizada?" (RODRIGUES, 2014, p. 28). 
Mais que se debruçar sobre a propriedade oficialmente disposta nos Códigos e sacralizada em discursos históricos, Rosa Congost (2007, p. 11) chama atenção para o estudo da "propriedade-realidade histórica" e não pela "propriedade-metáfora de uma determinada visão da história".

Não são apenas as condições legais da propriedade que interessam, mas sim o conjunto de elementos relacionados com as formas diárias de acessar os recursos, com as práticas diárias de distribuição social de renda, que podem condicionar e ser condicionados por diferentes formas de desfrutar dos direitos de propriedade e também pelos direitos e práticas de uso, isto é, pelas diferentes formas de ser proprietários (CONGOST, 2007).

É sob essa perspectiva que se optou por apresentar no presente artigo breves reflexões sobre a história do direito de propriedade no Brasil ao longo do século XVI e XIX discutindose não só os instrumentos legais e o aparato estatal que regulava o acesso à terra no Brasil, mas também a sua relação com os modelos socialmente construídos que influenciaram diretamente as relações jurídicas entre pessoas e coisas nesses períodos.

Considera-se a discussão extremamente necessária, especialmente quando os institutos e instrumentos jurídicos do direito vigente são utilizados como pressupostos para se observar e analisar o passado. Em relação ao direito fundiário brasileiro, conforme destacam Benatti (2003) e Paes (2018), podem ser citados os casos das cadeias dominiais. Nos moldes do direito fundiário e registral atual, a busca por origens dominiais remotas e anteriores ao Código Civil de 1916 pode ser problemática quando não se consideram as descontinuidades na construção do direito de propriedade no Brasil.

\section{Referências Bibliográficas}

BENATTI, J. H. Direito de Propriedade e Proteção Ambiental no Brasil: apropriação e o uso dos recursos naturais no imóvel rural. [s.1.] Universidade Federal do Pará, 2003.

CONGOST, R. Tierras, leyes, historia: estudios sobre la "gran obra de la propriedad". Barcelona: Crítica, 2007.

COSTA PORTO. O Sistema Sesmarial no Brasil. Brasília: Editora da UNB, 1965.

DINIZ, M. H. Sistemas de Registros de Imóveis. 11. ed. São Paulo: Saraiva, 2014. 
FERREIRA, E. R. Em cumprimento ao edital do reverendo vigário: os registros paroquiais no Pará - 1854-1860 (conflitos e tensões). Revista de História Econômica \& Economia Regional Aplicada, v. 7, n. 13, dez. 2012.

FONSECA, R. M. A "Lei de Terras" e o advento da propriedade moderna no Brasil. Anuário Mexicano de Historia del Derecho, n. 17, p. 97-112, 2005.

FONSECA, R. M. A cultura jurídica brasileira e a questão da codificação civil no século XIX. Revista da Faculdade de Direito UFPR, v. 44, n. 0, p. 61-76, 2006.

GROSSI, P. La propriedad y las propriedades. Un análisis histórico. Tradução: Angel M. López y López. Madrird: Editorial Civitas, 1992.

GROSSI, P. A propriedade e as propriedades na oficina do historiador. In: História da Propriedade e Outros Ensaios. Rio de Janeiro: Renovar, 2006. p. 1-84.

HESPANHA, A. M. A constituição do Império português. Revisão de alguns enviesamentos correntes. In: FRAGOSO, J.; BICALHO, M. F.; GOUVÊA, M. DE F. (Eds.). . O Antigo Regime nos trópicos: a dinâmica imperial portuguesa (séculos XVI-XVIII). Rio de Janeiro: Civilização Brasileira, 2001. p. 163-188.

HOLSTON, J. Cidadania Insurgente: disjunções da democracia e da modernidade no Brasil. São Paulo: Companhia das Letras, 2013.

MACHADO, L. DE O. R. Uma nova lei de terras para a Amazônia: o caso de Santarém, Pará. Brasília: Universidade de Brasília, 2011.

MATTOS NETO, A. J. DE. A posse agrária e suas implicações jurídicas no Brasil. Belém: CEJUP, 1988.

MOTTA, M. M. M. A grilagem como legado. In: MOTTA, M. M. M.; PIÑERO, T. L. (Eds.). Voluntariado e universo rural. Rio de Janeiro: Vício de leitura, 2002. p. 77-101.

MOTTA, M. M. M. Caindo por terra: um debate historiográfico sobre o universo rural do oitocentos. Lutas \& Resistências, v. 1, p. 42-59, 2006.

MUNIZ, P. Patrimônios dos Conselhos Municipais do Estado do Pará. Paris: Lisboa: Aillaud \& Cia., 1904.

PAES, M. A. D. Das Cadeias Dominiais Impossíveis: Posse e Título no Brasil Império. In: Propriedades em transformação: abordagens multidisciplinares sobre a propriedade no Brasil. 2018. [s.1.] Edgard Blücher Ltda, 2018. p. 41-57.

PEDROZA, M. Desafios para a história dos direitos de propriedade da terra no Brasil. Revista Em perspectiva, v. 2, n. 1, p. 7-33, 2016.

ROCHA, I. et al. Manual de Direito Agrário Constitucional: lições de Direito Agroambiental. Belo Horizonte: Editora Fórum, 2015. 
RODRIGUES, P. P. A Lei Hipotecária de 1864 originou a propriedade privada no Brasil? Tempos Históricos, v. 18, n. 2, p. 17-29, 2014.

SILVA, E. G. R. DA. Terras devolutas no pós 1988: Repercussões da jurisprudência dos Tribunais Superiores Brasileiros na estrutura fundiária da Amazônia Legal. Belém: Universidade Federal do Pará, 2018.

SILVA, L. O. Terras devolutas e latifúndio: efeitos da lei de 1850. 2. ed. Campinas: UNICAMP, 2008.

SIQUEIRA, G. S. Poucas ordenações, muitas expectativas: um estudo preliminar sobre processos, população e imprensa às vésperas do Código Civil de 1916. Revista de Direito Civil Contemporâneo - RDCC (Journal of Contemporary Private Law), v. 11, p. 159169, 30 jun. 2017.

STAUT JÚNIOR, S. S. A posse no direito brasileiro da segunda metade do século XIX ao Código Civil de 1916. [s.l.] Universidade Federal do Paraná, 2009.

TRECCANI, G. D. Violência e grilagem: instrumentos de aquisição da propriedade da terra no Pará. Belém: UFPA e ITERPA, 2001.

VARELA, L. B. Das Sesmarias à Propriedade Moderna: um estudo de história do direito brasileiro. Rio de Janeiro: Renovar, 2005.

WOLKMER, A. C. Paradigmas, historiografia crítica e direito moderno. Revista da Faculdade de Direito UFPR, v. 28, p. 55-67, 1994. 